\title{
Phenotypic Plasticity in Adult Worms of Schistosoma mansoni (Trematoda:Schistosomatidae) Evidenced by Brightfield and Confocal Laser Scanning Microscopies
}

\author{
Renata Heisler Neves, Michele Costa-Silva, Elaine Machado Martinez, \\ Thiago B Branquinho*, Regina Maria Figueiredo de Oliveira, Henrique Leonel Lenzi*/++, \\ Delir Corrêa Gomes**/++ , José Roberto Machado-Silva/ ${ }^{+} /++$
}

\begin{abstract}
Disciplina de Parasitologia, Departamento de Patologia e Laboratórios, Faculdade de Ciências Médicas, Universidade do Estado do Rio de Janeiro, Rua Prof. Manoel de Abreu 444, $5^{\circ}$ andar, 20551-170 Rio de Janeiro, RJ, Brasil *Departamento de Patologia

**Laboratório de Helmintos Parasitos de Vertebrados, Departamento de Helmintologia, Instituto Oswaldo Cruz-Fiocruz, Rio de Janeiro, RJ, Brasil
\end{abstract}

A comparative morphometric study was performed to identify host-induced morphological alterations in Schistosoma mansoni adult worms. A wild parasite population was obtained from a naturally infected rodent (Nectomys squamipes) and then recovered from laboratory infected $\mathrm{C} 3 \mathrm{H} / \mathrm{He}$ mice. Furthermore, allopatric worm populations maintained for long-term under laboratory conditions in Swiss Webster mice were passed on to N. squamipes. Suckers and genital system (testicular lobes, uterine egg, and egg spine) were analyzed by a digital system for image analysis. Confocal laser scanning microscopy (CLSM) showed details of the genital system (testicular lobes, vitelline glands, and ovary) and the tegument just below the ventral sucker. Significant morphological changes ( $p<$ $0.05)$ were detected in male worms in all experimental conditions, with no significant variability as assessed by CLSM. Significant changes $(p<0.05)$ were evident in females from the wild population related to their ovaries and vitelline glands, whereas allopatric females presented differences only in this last character. We conclude that $\mathrm{S}$. mansoni worms present the phenotypic plasticity induced by modifications in the parasite's microenvironment, mainly during the first passage under laboratory conditions.

Key words: Schistosoma mansoni - phenotypic plasticity - adult worms - Nectomys squamipes - C3H/He mice confocal laser scanning microscopy

Vertebrate animals live in different environments where they are exposed to several parasites. The outcome of this interaction is that both individuals have developed strategies for adaptation, aiming to reach an adjusted relationship (Hart 1992). In order to be established within the host, a successful parasite must possess the ability to tolerate the host immune responses (Zelmer 1998).

The trematode Schistosoma mansoni is a parasite worm naturally present in some rodents from Africa (Duplantier \& Sène 2000) and Neotropical region (Combes 1990, Théron et al. 1992, Rey 1993, Alarcón de Noya et al. 1997, D'Andrea et al. 2000, 2002). The water-rat Nectomys squamipes (Rodentia: Sigmondontinae) acts as a possible reservoir of schistosomiasis mansoni in Brazil (Rey 1993, D'Andrea et al. 2002) and can also be used as an alternative animal model in basic biological studies on schisto-

Financial support: Universidade do Estado do Rio de Janeiro and Fundação Oswaldo Cruz

This work is part of a MSc Thesis in Morphology, Instituto de Biologia, Uerj, RJ, Brasil

${ }^{+}$Corresponding author. Fax: +55-21-2587.6148. E-mail: machado@uerj.br

${ }^{++}$Fellowships CNPq

Received 23 July 2003

Accepted 21 January 2004 somiasis (Rodrigues-Silva et al. 1992, Maldonado Jr. et al. 1994, Ribeiro et al. 1998). Although this parasitism can provoke severe damages to humans, rodents are permissive hosts with life-long infections (Machado-Silva et al. 1997), which do not affect their life span (Rodrigues-Silva et al. 1992) or reproductive capacity (D'Andrea et al. 2000). $N$. squamipes develops peculiar granulomas consisting mainly of large macrophages, many of them full of schistosome pigment, characterizing an exudative-macrophage granuloma type, usually smaller than the equivalent granuloma type in mouse, and they never acquire Symmer's fibrosis pattern (Silva \& Andrade 1989, Costa-Silva et al. 2002). Such granulomas have been also observed in the rat Calomys callosus (Lenzi et al. 1995).

Parasitic flatworms that have been maintained in different hosts rather than in natural ones have undergone strong morphological changes (phenotypic plasticity) (Mouhaid et al. 1997). S. mansoni adult male worms were bigger in Rattus rattus than in R. norvegicus (Jourdane \& Imbert-Establet 1980) as well as in N. squamipes than in Swiss Webster (SW) mice. Moreover, they presented a shorter distance between suckers and the number of their testicular lobes was enhanced, when an isolate of $S$. mansoni from $N$. squamipes has been developed in albino mice (Machado-Silva et al. 1994). In the present study we demostrate the occurrence of phenotypic plasticity in $S$. mansoni adult worms induced in two host changes: $N$. squamipes to $\mathrm{C} 3 \mathrm{H} / \mathrm{He}$ mice and albino mice to $\mathrm{N}$. squamipes. 


\section{MATERIALS AND METHODS}

Animals - SW and C3H/He mice were supplied by the Animal Facility Center from the Oswaldo Cruz Foundation, Fiocruz, Rio de Janeiro, Brazil, and the laboratoryreared $N$. squamipes (Ns) by the Laboratory of Biology and Control of Schistosomiasis Mansoni, Department of Tropical Medicine, Oswaldo Cruz Institute, Rio de Janeiro (D'Andrea et al. 1996). The animals were kept in polypropylene cages $(40 \mathrm{~cm} \times 33 \mathrm{~cm})$ with stainless steel screened covers. All animals received a well-fed diet for mice (Nuvilab CR1, Colombo, Paraná, Brasil) and water ad libitum. Sacrifice of the animals followed standard ethical procedures for laboratory animals (GV-SOLAS 1985).

Experimental design

Wild S. mansoni population - Twelve N. squamipes were captured in a transmission area of schistosomiasis mansoni in the municipality of Sumidouro, state of Rio de Janeiro, Brazil (2202’46"S; 4241'21"W). They were killed under laboratory conditions and perfused for adult worm recovering (Machado-Silva et al. 1994) (Ibama license 061/ 2003 - CGFAU/LIC). This parasite population was termed as SN.

Sympatric laboratory-reared Biomphalaria glabrata snails, measuring $5 \mathrm{~mm}$ in shell diameter, were exposed to ten hatched miracidia collected from the rodent's feces. The snails were kept in glass vials with dechlorinated tap water and fed with fresh lettuce (Lacttuca sativa).

Seven-day-old $\mathrm{C} 3 \mathrm{H} / \mathrm{He}$ mice were exposed individually to cercariae ( $\mathrm{n} 50$ ) shed by the infected snails. After eight weeks post infection, the mice were killed by cervical dislocation and adult worms were recovered by portal-hepatic perfusion, establishing another isolate designated as SR.

Laboratory S. mansoni population - Laboratory-reared $N$. squamipes and SW mice (five to six week old) were infected with four different laboratory worm strains that have been maintained for more than five years under laboratory conditions in $B$. glabrata derived from the respective geographical areas: state of Pará $\left(01^{\circ} 28^{\prime} 03^{\prime \prime S}\right.$; $\left.48^{\circ} 29^{\prime} 18^{\prime \prime W}\right)$, state of Ceará $\left(03^{\circ} 45^{\prime} 47^{\prime \prime} \mathrm{S} ; 38^{\circ} 31^{\prime} 23^{\prime \prime W}\right)$, state of Rio Grande do Norte $\left(05^{\circ} 45^{\prime} 54^{\prime \prime} \mathrm{S} ; 35^{\circ} 12^{\prime} 04^{\prime \prime W}\right)$, and state of Pernambuco ( $\left.08^{\circ} 45^{\prime} 48^{\prime \prime} \mathrm{S} ; 3^{\circ} 54^{\prime} 47^{\prime \prime} \mathrm{W}\right)$. The parasites isolated from $N$. squamipes and SW were designated as $\mathrm{BE} / \mathrm{Ns}, \mathrm{CE} / \mathrm{Ns}, \mathrm{CM} / \mathrm{Ns}$, and $\mathrm{CMO} / \mathrm{Ns}$ or $\mathrm{BE} / \mathrm{Sw}$, $\mathrm{CE} / \mathrm{Sw}, \mathrm{CM} / \mathrm{Sw}$, and $\mathrm{CMO} / \mathrm{Sw}$, respectively. All populations were routinely maintained in SW mice and B. glabrata snail host at the Department of Malacology, IOC-Fiocruz, Rio de Janeiro, Brazil.

Nine weeks pos-infection, the animals were killed (cervical dislocation) and perfused for adult worm recovering (Smithers \& Terry 1965). This set of experiment was regarded as in allopatric condition, because each worm population came from a different geographical area.

Morphometric analysis of adult worms - The worms were fixed in AFA (alcohol 95\%, formalin 3\%, and glacial acetic acid $2 \%$ ), stained with chloride carmine, clarified in methyl salicylate and preserved as whole-mounts (Neves et al. 1998).

Brightfield microscopic (Olympus BX50) images were captured by an analogue camera (Sony, 640 x 480 pixels,
RGB) and transferred to a computer containing software for image analysis (Image Pro Plus - Media Cybernetics, US). The following morphological characters were analyzed: oral and ventral sucker areas, distance between them (both sexes); number, area, major and minor diameter, and perimeter of the testicular lobes; area, major and minor diameter, perimeter of the egg and its spine (Neves et al. 1998). All measurements are in micrometers, unless otherwise stated. Five specimens from each population (SN, $\mathrm{SR}, \mathrm{BE} / \mathrm{Ns}$, and BE/Sw) were also studied by confocal laser scanning microscopy (CLSM) (LSM-410, Zeiss), analyzing the following morphometric characteristics: thickness of the tegument below the ventral sucker (for both sexes); length and width of the first, third, and last normal testicular lobes; length, width, and area of the vitelline glands, and length and width of the ovary. On what refers to the body length, values were those previously reported by Machado-Silva et al. (1995): $9.5 \pm 1.3 \mathrm{~mm}$ for the wild strain and $6.9 \pm 1.55 \mathrm{~mm}$ for laboratory strain.

Statistical analysis - The data were submitted to the Student's $t$-test (brightfield microscopy) and MannWhitney test (confocal microscopy), and statistical significance was assessed at $\mathrm{p} \leq 0.05$. The statistical program SPSS 9.0 for Windows was used to facilitate calculations.

\section{RESULTS}

Wild strain - Biometric evaluations of male worms from the SN population showed higher values than those observed in SR, except in relation to the number of testicular lobes. Most differences were considered to be significant $(\mathrm{p}<0.05)$, except for the major and minor diameters of the testicular lobes (Table I). Testicular lobes in atypical position (supernumerary) were present in adult worms from both populations. Two specimens (SN population) presented only one supernumerary lobe, while six worms had one, three or six lobes (SR population). The distance between the last testicular lobe and the nearest supernumerary one in the SN population varied from $254.66 \mu \mathrm{m}$ to $517.24 \mu \mathrm{m}$, while in the SR population the occurrence of higher number of supernumerary testicular lobes was followed by longer distance between them. For instance, in case with three and six testicular lobes the distances were $976.63 \mu \mathrm{m}$ and $1251.80 \mu \mathrm{m}$, respectively.

All female characteristics of the SR population were bigger than those from the SN population $(\mathrm{p}<0.05)$ (Table I).

Both male and female worms from the SR population examined by CLSM presented all measurements bigger than those from the SN population, except for the thickness of the tegument in females. Only measurements of the ovary and width of the vitelline glands were significantly different $(\mathrm{p}<0.05)$ (Table II).

Laboratory strain - Measurements of male allopatric specimens isolated from SW mice were bigger than those from $N$. squamipes, except for the $\mathrm{CMO} / \mathrm{Sw}$ population $(\mathrm{p}<0.05)$. The testicular lobe number was the only character that did not show significant changes between laboratory populations, except for $\mathrm{CMO} / \mathrm{Sw}$ (Table I).

One (BE/Sw and CE/Sw populations) or two $(\mathrm{CM} / \mathrm{Sw})$ supernumerary testicular lobes were found in rats, and three $(\mathrm{BE} / \mathrm{Sw})$ or five $(\mathrm{CE} / \mathrm{Sw})$ in mice. In the latter 


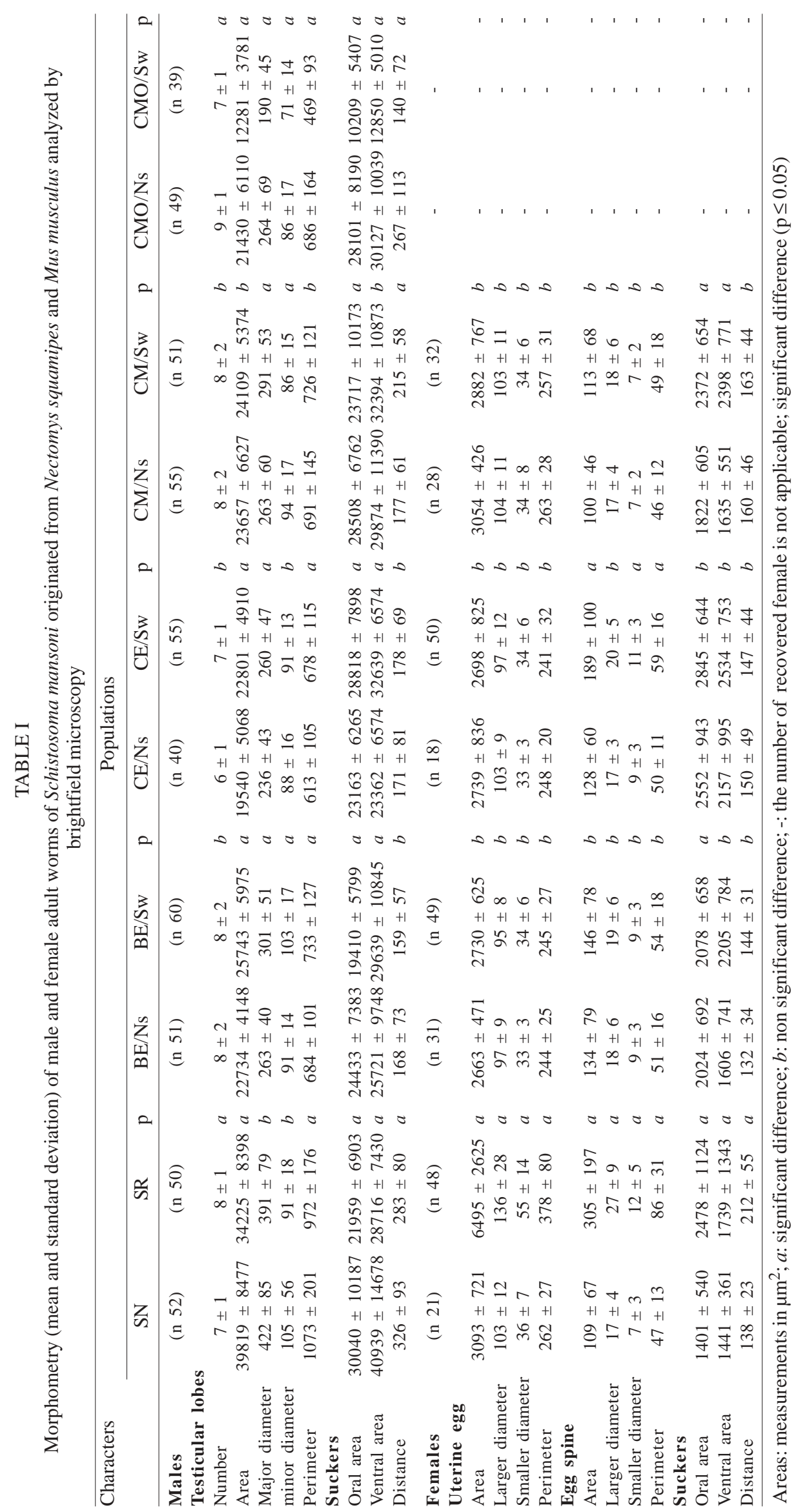


$(\mathrm{CM} / \mathrm{Sw})$ and in both types of hosts $(\mathrm{CMO} / \mathrm{Sw})$ supernumerary testicular lobes were not detected. In $N$. squamipes, the distance between the last testicular lobe and the nearest supernumerary one varied from $8.4 \mu \mathrm{m}$ to $237.17 \mu \mathrm{m}$, while in mice it changed from $49.24 \mu \mathrm{m}$ to $1493.19 \mu \mathrm{m}$.

Few differences were observed among females from allopatric infra-populations (Table I).

In male and female specimens from $\mathrm{BE} / \mathrm{Ns}$ and $\mathrm{BE} / \mathrm{Sw}$ populations analyzed by CLSM, only the area and length of the vitelline glands presented significant differences $(\mathrm{p}<0.05)$ (Table II).

\section{DISCUSSION}

It is well known that the host exerts a strong influence on the morphological features of adult trematodes (Watson \& Pike 1993, Adela-Varelo et al. 1998). The outcome of this interaction is that specimens maintained in other hosts rather than their normal ones display a phenotypic plasticity (Mouhaid et al. 1997). The data herein presented reinforce our previous observations indicating that $S$. mansoni male worms undergone host-induced morphological changes already in their first passage under laboratory conditions (Machado-Silva et al. 1994). Probably, phenotypic plasticity may occur because adult worms are established in an environment other than their normal one.

Despite the fact that phenotypic plasticity occurred either in passages from rat to mouse or vice-versa, it seems that the repercussions of environment modifications are more prominent in wild strain conditions. While wild strain male and female worms were quite affected, lesser significant morphological modifications related to laboratory populations were found. It appears that only one passage in a new host is not enough to induce noticeable phenotype variability in populations that have been cycled for long-term under laboratory conditions. Probably this event is due to a "bottle neck" pressure inducing parasite isolates to clonality. For this reason, BE/Ns, BE/Sw, CE/ $\mathrm{Ns}, \mathrm{CE} / \mathrm{Sw}, \mathrm{CM} / \mathrm{Ns}$, and $\mathrm{CM} / \mathrm{Sw}$ populations presented few comparative changes among them in both studied hosts, which were more related to measurements of the larger and smaller testicular diameters. Measurements obtained from female characters, such as uterine eggs, egg spine, and ovary were more or less homogeneous. However, the CMO population did not behave as described above, since all its morphological measurements were deeply altered. Interestingly, the CMO population was isolated from a naturally infected Cricetidae host. It was not possible to determine if the environmental conditions that affected the population variability were favorable or unfavorable to the parasites.

The physiological determinants of the phenotypic plasticity are not known but we suppose that wild rodents can give all physiological conditions (nutritional and hormonal) required to the development and maturation of the parasites. Recent findings have indicated that schistosome development was strikingly impaired in interkeukin (IL-7)-deprived mice (Wolowczuk et al. 1999a). IL-7 seems to favor the parasite responsiveness to host endocrine factors (Wolowczuk et al. 1999b).

This fact raises questions concerning the relationship between phenotypic plasticity and biological or physiological implications. It is more likely that male worms display a more pronounced physiological activity than females do. Some biochemical male-female interplay is required for female's nutrition and sexual maturation (Skelly et al. 1998). Male factors affect very specific cellular events in the female (Kunz 2001). Furthermore, it must be pointed out that male worms are more sensitive to the modifications of the hormonal environment induced by the constitutive expression of IL-7 (Roye et al. 2001).

From the morphological point of view, male worms have developed suckers and a well-developed musculature that allow migration against the portal flow to the mesenteric

TABLE II

Morphometry (mean and standard deviation) of male and female adult worms of Schistosoma mansoni originated from Nectomys squamipes and Mus musculus analyzed by confocal laser microscopy

\begin{tabular}{|c|c|c|c|c|c|c|}
\hline \multirow[t]{2}{*}{ Characters } & \multicolumn{5}{|c|}{ Populations } & \multirow[b]{2}{*}{$\mathrm{p}$} \\
\hline & $\mathrm{SN}(\mathrm{n} 5)$ & $\mathrm{SR}(\mathrm{n} 5)$ & $\mathrm{p}$ & BE/Ns (n 5) & BE/Sw (n 5) & \\
\hline \multicolumn{7}{|l|}{ Males } \\
\hline \multicolumn{7}{|l|}{ Testicular lobes } \\
\hline Length & $71 \pm 26$ & $73 \pm 9$ & $b$ & $77 \pm 10$ & $71 \pm 11$ & $b$ \\
\hline Width & $46 \pm 12$ & $59 \pm 11$ & $b$ & $43 \pm 6$ & $40 \pm 3$ & $b$ \\
\hline Tegument - thickness & $8 \pm 1$ & $8 \pm 2$ & $\mathrm{~b}$ & $11 \pm 2$ & $12 \pm 3$ & $\mathrm{~b}$ \\
\hline \multicolumn{7}{|l|}{ Females } \\
\hline \multicolumn{7}{|l|}{ Vitelline glands (n 10) } \\
\hline Area & $483 \pm 139$ & $569 \pm 134$ & $b$ & $898 \pm 271$ & $501 \pm 130$ & $a$ \\
\hline Length & $41 \pm 8$ & $43 \pm 9$ & $b$ & $55 \pm 13$ & $40 \pm 4$ & $a$ \\
\hline Width & $13 \pm 2$ & $16 \pm 2$ & $a$ & $19 \pm 1$ & $17 \pm 5$ & $b$ \\
\hline \multicolumn{7}{|l|}{ Ovary } \\
\hline Length & $306 \pm 25$ & $370 \pm 40$ & $a$ & $364 \pm 89$ & $405 \pm 100$ & $b$ \\
\hline Width & $83 \pm 5$ & $113 \pm 13$ & $a$ & $132 \pm 27$ & $115 \pm 12$ & $b$ \\
\hline Tegument - thickness & $3.5 \pm 0.5$ & $2.9 \pm 0.6$ & $\mathrm{~b}$ & $2.5 \pm 0.8$ & $2.4 \pm 0.8$ & $\mathrm{~b}$ \\
\hline
\end{tabular}

Areas: measurements in $\mu^{2}$; $a$ : significant difference; $b$ : non significant difference; significant difference $(\mathrm{p} \leq 0.05)$ 
and colonic venules. In this niche, female worms begin oviposition (Mair et al. 1998, Morand \& Müller-Graf 2000). Consequently, any morphological change could affect egglaying. Obviously, these questions still remain to be elucidated.

Although wild strain and laboratory strain worms displayed few significant morphological differences related to their reproductive system, as assessed by CLSM, our results demonstrated that all measures became bigger after passages from wild rodent to mouse or from mouse to wild rodent hosts. When body size was compared to those obtained by Machado-Silva et al. (1995), the results showed to be similar.

The unusual finding of supernumerary testicular lobes confirms our previous studies both in mice and N. squamipes (Machado-Silva et al. 1994, Neves et al. 1998). However, a detailed study by CLSM failed to demonstrate any evidence that this atypical structure is an active component of the reproductive system, once they are isolated and without expression of spermatogenesis (MachadoSilva et al. 1998). New morphological studies (transmission electron microscopy, immunohistochemistry and other) are still required to clarify their functions.

Both the reproductive system and the development of adult male worm tegument in S. mansoni depend on the physiological characteristics of the host, such as nutritional and hormonal states. Thus, maturation of the tegument is delayed or does not occur in a non-permissive host (R. norvegicus) (Senft et al. 1978). However, if worms are transplanted to a permissive host their normal somatic development is recovered (Cioli et al. 1977). It was not purpose of this current investigation to study the structural organization of the tegument, since both used hosts are permissive, assuring a full somatic development (Machado-Silva et al. 1994, 1997). Probably, this explains why no significant differences were found in relation to the thickness of the tegument either in male or female worms evaluated by CLSM. Nevertheless, little is known about a possible correlation between the thickness of the tegument and the physiological conditions of the host. Even if the host is a permissive one, his nutritional state can influence the development of the parasite. Host diets deficient in protein can lead to reductions in body size in adult worms (Poulin 1996). Recently, we have demonstrated that male adult worms isolated from mice with protein deficiency display thinner tegument than well-fed controls (Neves et al. 2001).

The results here presented confirm the occurrence of phenotypic plasticity in $S$. mansoni adult worms, as previously described by scanning electron microscopy in isolates of the same species and in S. margrebowie and $S$. mattheei (Kruger et al. 1988, Machado-Silva et al. 1994). In organisms inhabiting heterogeneous environments, genotypes can produce different phenotypes under different conditions (Poulin 1996). We would like to highlight that phenotypic plasticity is a phenomenon that should be considered by those researchers related to trematodes' systematic (Monis 1999). Thus, if one recovers a same parasitic flatworm from several hosts with morphological variability among them, it does not mean that the isolates are different species. Such results could be only due to genotypes, producing suited phenotypes under adverse physiological conditions, such as a host different from the usual one. However, it is still unknown how genotypes control such phenotypes. There are strong biological, evolutionary and immunological arguments for predicting extensive polymorphism among helminth parasites, but relatively little data and few instances from which the selective forces acting on parasite diversity can be discerned. The study of helminth polymorphisms across the whole species in the wild, and driven by many possible forces from host, vector and environment, is sure to provide many such fascinating and insightful advances and make an essential contribution to the control of helminth diseases (Maizels \& KurniawanAtmadja 2002). Last but not least, linking proteome and genome could clarify this issue (Asthon et al. 2001), contributing to a better understanding of the occurrence of possible alterations.

\section{ACKNOWLEDGEMENTS}

To Departamento de Malacologia, Instituto Oswaldo Cruz for providing populations of S. mansoni. To Roberto Magalhães Pinto for critical comments on the manuscript.

\section{REFERENCES}

Adela-Varelo M, Dolores-Marco M, Fons R, Mas-Coma S 1998. Fasciola hepatica development in the experimentally infected black rat Rattus rattus. Parasitol Res 84: 188-194.

Alarcón De Noya B, Pointier JP, Colmenares C, Théron A, Balzan C, Cesari IM, González S, Noya O 1997. Natural Schistosoma mansoni infection in wild rats from Guadeloupe: parasitological and immunological aspects. Acta Trop 68: 11-21.

Asthon PD, Curwen RS, Wilson RA 2001. Linking proteome and genome: how to identify parasite proteins. Trends Parasitol 17: 198-202.

Cioli D, Knopf PM, Senft AW 1977. A study of Schistosoma mansoni transferred into permissive and nonpermissive hosts. Int J Parasitol 7: 293-297.

Combes C 1990. Where do human schistosomes come from? An evolutionary approach. Trends Ecol Evol 5: 334-337.

Costa-Silva M, Rodrigues-Silva R, Hulstijn M, Neves RH, Panasco MS, Lenzi HL, Machado-Silva JR 2002. Natural Schistosoma mansoni infection in Nectomys squamipes: histopathological and morphometric analysis in comparison to experimentally infected $N$. squamipes and $\mathrm{C} 3 \mathrm{H} / \mathrm{He}$ mice. Mem Inst Oswaldo Cruz 97: 129-142.

D'Andrea PS, Horta C, Cerqueira R, Rey L 1996. Breeding of the water rat (Nectomys squamipes) in the laboratory. Lab Animals 30: 369-376.

D’ Andrea PS, Fernandes FA, Cerqueira R, Rey L 2002. Experimental evidence and ecological perspectives for the adaptation of Schistosoma mansoni Sambon, 1907 (Digenea: Schistosomatidae) to a wild host, the water-rat, Nectomys squamipes Brants, 1827 (Rodentia: Sigmodontinae). Mem Inst Oswaldo Cruz 97: 11-14.

D'Andrea PS, Maroja LS, Gentile R, Cerqueira R, Maldonado Jr A, Rey L 2000. The parasitism of Schistosoma mansoni (Digenea:Trematoda) in a naturally infected population of water rats, Nectomys squamipes (Rodentia:Sigmondontinae) in Brazil. Parasitology 120: 573-582.

Duplantier JM, Sène M 2000. Rodents as reservoir hosts in the transmission of Schistosoma mansoni in Richard-Toll, Senegal, West Africa. J Helminthol 74: 129-135.

GV-SOLAS - Working Committee for the Biological Character- 
ization of Laboratory Animals 1985. Guidelines for specification of animals and husbandry methods when reporting the results of animal experiments. Lab Animals 19: 106108.

Hart BL 1992. Behavioral adaptations to parasites: an ethological approach. J Parasitol 78: 256-265.

Jourdane J, Imbert-Establet D 1980. Etude expérimentale de la permissivité du rat sauvage (Rattus rattus) de Guadeloupe á l'egard de Schistosoma mansoni. Hyphotese sur le rôle du cet hôte dans la dynamique des foyers naturels. Acta Trop 37: 41-51.

Kruger FJ, Hamilton-Attwell VL, Tiedt L, Visser PS, Joubert PH 1988. Notes on the occurrence of tubercular spines in Schistosoma margrebowiei and Schistosoma mattheei. Onderstepoort J Vet Res 55: 187-189.

Kunz W 2001. Schistosome male-female interaction: induction of germ-cell differentiation. Trends Parasitol 17: 227-231.

Lenzi JA, Mota EM, Pelajo-Machado M, Paiva RAN, Lenzi HL 1995. Callomys callosus: an alternative model to study fibrosis in schistosomiasis mansoni. The pathology of acute phase. Mem Inst Oswaldo Cruz 90: 311-318.

Machado-Silva JR, Lanfredi RM, Gomes DC 1997. Morphological study of adult male worms of Schistosoma mansoni by scanning electron microscopy. Mem Inst Oswaldo Cruz 92: 647-653.

Machado-Silva JR, Galvão C, Oliveira RMF, Presgrave OAF, Gomes DC 1995. Schistosoma mansoni Sambon, 1907: comparative morphological studies of some Brazilian strains. Rev Inst Med Trop São Paulo 37: 441-447.

Machado-Silva JR, Galvão C, Presgrave OAF, Rey L, Gomes DC 1994. Host-induced morphological changes of Schistosoma mansoni Sambon, 1907 male worms. Mem Inst Oswaldo Cruz 89: 411-416.

Machado-Silva JR, Pelajo-Machado M, Lenzi HL, Gomes DC 1998. Morphological study of adult male worms of Schistosoma mansoni Sambon, 1907 by confocal laser scanning microscopy. Mem Inst Oswaldo Cruz 93: 303-307.

Mair GR, Maule AG, Shaw C, Halton DW 1998. Muscling in on parasitic flatworms. Parasitol Today 14: 73-76.

Maizels RM, Kurniawan-Atmadja 2002. Variation and polymorphism in helminth parasites. Parasitology 125: S25S37.

Maldonado Jr A, Machado-Silva JR, Rodrigues-Silva R, Lenzi HL, Rey L 1994. Evaluation of the resistance to Schistosoma mansoni infection in Nectomys squamipes (Rodentia:Cricetidae), a natural host of infection in Brazil. Rev Inst Med Trop São Paulo 36: 303-307.

Monis PT 1999. The importance of systematics in parasitology research. Int J Parasitol 29: 381-388.

Morand S, Müller-Graf CDM 2000. Muscles or testes? Comparative evidence for sexual competition among dioecious blood parasites (Schistosomatidae) of vertebrates. Parasitology 120: 45-56.

Mouhaid G, Casanova JC, Moné H 1997. Plasticidad fenotípica y determinacion sistemática de parásitos: el caso de Echinoparyphium elegans. Acta Parasitol Portuguesa 4: 127.

Neves RH, Machado-Silva JR, Pelajo-Machado M, Oliveira SA, Coutinho EM, Lenzi HL, Gomes DC 2001. Morpho- logical aspects of Schistosoma mansoni adult worms isolated from nourished and undernourished mice: a comparative analysis by confocal laser scanning microscopy. Mem Inst Oswaldo Cruz 96: 1013-1016.

Neves RH, Pereira MJS, Gomes DC, Oliveira RMF, MachadoSilva JR 1998. Morphometric differences of adult worms from sympatric samples of Schistosoma mansoni Sambon, 1907 isolated from rodents and humans. Mem Inst Oswaldo Cruz 93: 309-312.

Poulin R 1996. The evolution of the life history strategies in parasitic animals. Adv Parasitol 37: 107-134.

Rey L 1993. Non-human vertebrate hosts of Schistosoma mansoni and schistosomiasis transmission in Brazil. Res Rev Parasitol 53: 13-25.

Ribeiro AC, Maldonado Jr. A, D’ Andrea PS, Vieira GO, Rey L 1998. Susceptibility of Nectomys rattus (Pelzen, 1883) to experimental infection with Schistosoma mansoni (Sambon, 1907): a potential reservoir in Brazil. Mem Inst Oswaldo Cruz 93: 295-299.

Rodrigues-Silva R, Machado-Silva JR, Faerstein NF, Lenzi HL, Rey L 1992. Natural infection of wild rodents by Schistosoma mansoni. Parasitological aspects. Mem Inst Oswaldo Cruz 87: 271-276.

Roye O, Delacre M, Williams IR, Auriault C, Wolowczuk I 2001. Cutaneous interleukin-7 transgenic mice display a propitious environment to Schistosoma mansoni infection. Parasite Immunol 23: 133-140.

Senft AW, Gibler WB, Knopf PM 1978. Scanning electron microscope observations on tegument maturation in Schistosoma mansoni grown in permissive and non-permissive hosts. Am J Trop Med Hyg 27: 258-266.

Silva TM, Andrade ZA 1989. Natural infection of wild rodents by Schistosoma mansoni. Mem Inst Oswaldo Cruz, 84: 227-235.

Skelly PJ, Tielens AGM, Shoemaker CB 1998. Glucose transport and metabolism in mammalian-stage schistosomes. Parasitol Today 14: 402-406.

Smithers SR, Terry RJ 1965. The infection of laboratory hosts with cercariae of Schistosoma mansoni and the recovery of the adults worms. Parasitology 55: 695-700.

Théron A, Pointier JP, Morand S, Imbert-Establet D, Borel G 1992. Long-term dynamics of natural populations of Schistosoma mansoni among Rattus rattus in patchy environment. Parasitology 104: 291-298.

Watson JJ, Pike AW 1993. Variation in the morphology of adult Apatemon gracilis Rudolphi, 1819 (Digenea:Strigeidae) reared in different avian hosts. Syst Parasitol 26: 33-38.

Wolowczuk I, Olivier R, Nutten S, Delacre M, Trottein F, Aurialt C 1999a. Role of interleukin-7 in the relation between Schistosoma mansoni and its definitive vertebrate host. Microbes Infect 1: 545-551.

Wolowczuk I, Olivier R, Nutten S, Delacre M, Trottein F, Aurialt C 1999b. Infection of mice lacking interleukin-7 (IL-7) reveals an expected role for IL-7 in the development of the parasite Schistosoma mansoni. Infect Immun 67: 4183-4190.

Zelmer DA 1998. An evolutionary definition of parasitism. Int J Parasitol 28: 531-533. 